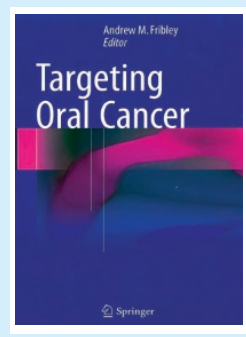

\section{TARGETING ORAL CANCER}

Andrew M. Fribley (Editor)

Springer

price $\mathrm{f} 89.50$ pp 302

ISBN 978-3-319-27645-8ISBN

This title is intended for professionals, researchers and postgraduates in dentistry, medicine, and oral and maxillofacial surgery. It is a comprehensive resource for those in clinical practice and research wishing to gain a more in depth knowledge of the complex and rapidly evolving area of oral cancer.

This well referenced book is carefully organised; each of the 12 chapters has an abstract, leading to detailed discussion and subsections with a short conclusion. Written by a total of 36 authors, it has been edited and structured well in three clear sections: epidemiology and current treatment modalities, molecular progression, biomarkers and stem cells, and finally current treatment trends and novel therapeutic approaches.

The first section guides the reader through the demographics of oral and pharyngeal cancer to the role of human papilloma virus (HPV). This chapter was especially interesting with good use of diagrams and histology slides. It explores the relationship between sexual behaviours and HPV, the history of the disease and HPV positive tumour prognosis. The section continues to describe staging and both surgical management and outcomes. Part one concludes with a chapter on chemotherapy use in squamous cell cancer.

In the next section, a comprehensive three chapters delve into the molecular signalling, biomarkers and role of cancer stem cells in recurrence. Diagrams and tables aid reader understanding in what is a very complex and often challenging area.

Part three covers coagulation mediators, protein response and immunotherapy. The final chapter was particularly engaging suggesting treatment of tumours intra orally with mucosal therapies with good use of clinical photographs.

The only criticism of this book is that it is not the most accessible in terms of volume and content for the clinician. The focus on the science surrounding oral cancer at the molecular level is beyond the scope of most practitioners' day to day requirements. It is therefore more suited to those wishing to gain a detailed knowledge of the disease especially at the cellular level.

In summary, this title is useful in extending knowledge of the key aspects of the disease and would be ideal for those undertaking specific research at postgraduate level. Overall, this book is an informative read for those involved with oral cancers wishing to obtain up-to-date, well researched information. It is indeed a targeted resource to all aspects of this disease.

C. Whyte

\title{
Annual Old Students' dinner
}

The UCH Dental School Old Students' Association (UCH OSA) will be holding its annual dinner from $7 \mathrm{pm}$ on 19 November 2016 at the Holborn Bars, 138-142 Holborn, London, EC1N 2NQ, with the Hon President, Dr Peter Collins. The closing date for reservations is 11 November 2016 and further information is available from Sandip Popat, Hon Secretary at UCHOSA2016@gmail.com.

This year, for the first time, notices are being sent by email only and so members and old students reading this are asked to contact those who might not otherwise have received such notices. All former students, staff, and partners are welcome.

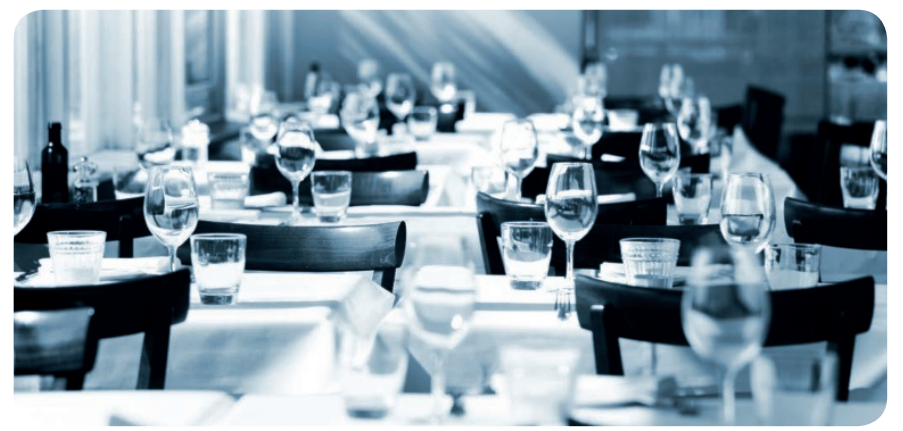

